AperTO - Archivio Istituzionale Open Access dell'Università di Torino

Myostatin regulates the fibrogenic phenotype of hepatic stellate cells via c-jun $\mathbf{N}$-terminal kinase activation

This is a pre print version of the following article:

Original Citation:

Availability:

This version is available http://hdl.handle.net/2318/1717634

since 2019-11-25T17:39:21Z

Published version:

DOI:10.1016/j.dld.2019.03.002

Terms of use:

Open Access

Anyone can freely access the full text of works made available as "Open Access". Works made available under a Creative Commons license can be used according to the terms and conditions of said license. Use of all other works requires consent of the right holder (author or publisher) if not exempted from copyright protection by the applicable law. 


\title{
Myostatin regulates the fibrogenic phenotype of hepatic stellate cells via c-jun $\mathbf{N}$-terminal kinase activation
}

Wanda Delogua,1, Alessandra Caligiuri a,1, Angela Provenzanoa, Chiara Rossoc, Elisabetta Bugianesic, Andrea Corattid, Jose Macias-Barragana,2, Sara Galastri a,3, Giovanni Di Mairaa, Fabio Marraa,b,*

a Dipartimento di Medicina Sperimentale Clinica, University of Florence, Florence, Italy b Research Center Denothe, University of Florence, Florence, Italy c Dipartimento di Scienze Mediche, University of Turin, Turin, Italy d SOD Chirurgia Oncologia a indirizzo robotico, Azienda Ospedaliero-Universitaria Careggi, Florence, Italy

\begin{abstract}
Background \& aims: Myostatin is mainly expressed in skeletal muscle, where it negatively regulates trophism. This myokine is implicated in the pathophysiology of nonalcoholic steatohepatitis, an emerg-ing cause of liver fibrosis. In this study we explored the effects of myostatin on the biology of hepatic stellate cells.
\end{abstract}

Methods: The effects of myostatin were assessed both in LX-2 and in human primary stellate cells. Cell migration was determined in Boyden chambers. Activation of intracellular pathways was evaluated by Western blotting. Procollagen type 1 secretion was measured by enzyme immunoassay. The role of c-Jun N-terminal kinase was assessed by pharmacologic and genetic inhibition.

Results: Activin receptor-2B was up-regulated in livers of mice with experimental fibrosis, and detectable in human stellate cells. Serum myostatin levels increased in a model of acute liver injury. Myostatin reduced HSC proliferation, induced cell migration, and increased expression of procollagen type1, tis-sue inhibitor of metalloproteinase-1, and transforming growth factor-__. Myostatin activated different signaling pathways, including c-Jun N-terminal kinase and Smad3. Genetic and/or pharmacologic inhi-bition of c-Jun N-terminal kinase activity significantly reduced cell migration and procollagen secretion in response to myostatin.

Conclusions: Activation of activin receptor-2B by myostatin modulates the fibrogenic phenotype of human stellate cells, indicating that a myokine may be implicated in the pathogenesis of hepatic fibrosis. 


\section{Introduction}

Myostatin, also known as growth differentiation factor-8, is ahighly conserved protein belonging to the transforming factor-_family. Expression of myostatin is detected primarily in skeletalmuscle, and is a negative modulator of muscle growth and trophism[1]. In fact, mutations or targeted deletion in mammalian speciescause muscle hypertrophy and hyperplasia [2]. Accordingly, myostatin has been implicated in the pathogenesis of muscle wastingin different conditions, including cancer cachexia [3]. The actionof myostatin is mediated by interaction with activin receptor-2B(ActR2B) [4] and results in activation of a Smad3/4 complex and toits translocation to the nucleus, where target genes are activated.Recent findings suggest a possible involvement of myostatin in theabnormalities associated with the metabolic syndrome. Myostatin-deficient mice have a significant reduction in fat accumulation,despite normal food intake, and show improved insulin sensitiv-ity in conditions of obesity [5,6]. In humans, elevated expressionlevels of myostatin have been reported in the muscle of patientswith type 2 diabetes, and myostatin expression is reduced in theskeletal muscle of obese individuals undergoing weight loss $[1,7,8]$.Skeletal muscle is a relevant part of the network coordinatingmetabolism and participates in the complex alterations occurringin the metabolic syndrome and insulin resistance [9]. Nonalcoholic fatty liver disease (NAFLD) is the hepatic counterpart of this dis-order and is characterized by accumulation of fat, predominantly in the form of triglycerides [10]. NAFLD is associated with a higher risk of liverrelated and all-cause mortality, due to the occurrence of nonalcoholic steatohepatitis (NASH), which may lead to the appear-ance of cirrhosis and its complications, including hepatocellular carcinoma [11]. Recent studies have indicated that the presence of fibrosis is a major risk factor for progression of NAFLD and mortality $[12,13]$. Thus, understanding the molecular and cellular mechanisms lead-ing to fibrosis in this setting is of crucial importance to design appropriate management strategies for patients with NASH. Com-pelling evidence in the past two decades has highlighted the pivotal role played by hepatic stellate cells (HSC) as the key effectors in the pathogenesis of fibrosis in different chronic liver diseases, including NASH [14,15]. Although fibrosis is the ultimate out-come of all chronic liver diseases, there is accumulating evidence for disease- and context-specific mechanisms that may modulate or drive hepatic fibrogenesis [16]. In this respect, no informa-tion is currently available concerning a possible contribution of myokines, i.e. cytokines predominantly expressed in skeletal mus-cle, on the cellular and molecular mechanisms of fibrogenesis. Here we show that myostatin is a novel modulator of the biology of HSC, differentially affecting proliferation, migration and expres-sion of extracellular matrix components, via activation of the c-Jun N-terminal kinase (JNK) pathway. 


\section{Materials and methods}

\section{Materials}

Recombinant human myostatin and platelet-derived growthfactor-BB were from Peprotech (Rocky Hill, NJ). Monoclonal anti-bodies against vinculin and _-actin were from Sigma Chemical Co.(St. Louis, MO). Polyclonal antibodies against total- and phospho-rylated JNK were from Santa Cruz Biotechnology (Santa Cruz, CA).Phosphorylation-specific antibodies against ERK1/2, Akt (Ser473)and Smad3 were from Cell Signaling Technology (Danvers, MA).SP600125 was from Sigma Chemical Co. (Sigma Aldrich Spa, Milano,Italy). Procollagen type 1 C-peptide (PIP) EIA kit was purchasedfrom Takara Bio (Mountain View, CA). The anti-Activin ReceptorType IIB antibody - N-terminal (ab135635) was purchased fromAbcam (Cambridge, UK). Anti- _-smooth muscle actin antibodieswere from Sigma.

\section{Cell cultures}

LX-2 cells were a kind gift of Dr. Scott L. Friedman (MountSinai School of Medicine, New York, NY). Primary human HSCwere isolated as previously described in detail and used aftercomplete transition towards a myofibroblast-like phenotype [17].Both cell types were cultured in Iscove’s modified Dulbecco'smedium supplemented with $2.0 \mathrm{mmol} / \mathrm{L}$ of glutamine, $0.1 \mathrm{mmol} / \mathrm{Lof}$ nonessential amino acids, $1.0 \mathrm{mmol} / \mathrm{L}$ of sodium pyruvate,antibiotic-antimycotic solution and $20 \%$ foetal bovine serum (allprovided by Gibco Laboratories, Grand Island, NY). Cells were serumdeprived for $48 \mathrm{~h}$ before all the experiments.MTT assayCell proliferation was determined measuring the cellularmetabolic activity using the 3-(4,5-dimethylthiazolyl-2)-2, 5diphenyltetrazolium bromide (MTT) assay, as described elsewhere[18]. Serum-starved LX-2 cells were exposed to different concentra-tions of myostatin or $10 \mathrm{ng} / \mathrm{ml}$ PDGF-BB, used as positive control,for 24, 48, or $72 \mathrm{~h}$. Cells were then treated with MTT (5 mg/ml inPBS and then with lysis solution (20\% (w/v) SDS, 50\% (v/v) N,N-dimethylformamide, 2\% (v/v) acetic acid and 25 mM $\mathrm{HCl}, \mathrm{pH}$ 4.7).Samples were read at $590 \mathrm{~nm}$ in a Multiskan FC plate reader.

\section{Migration assay}

These experiments were performed essentially as previouslydescribed, using Boyden chambers equipped with 8-_m poros-ity polyvinylpyrrolidone-free polycarbonate filters [17]. Wheninhibitors were used, cultured cells were treated with drugs to betested or with their vehicle for 15 min before trypsinization, andequal concentrations were added to both chambers of the Boydenapparatus. 
RNA isolation and quantitative real time PCR

Total RNA was isolated using the Nucleo Spin RNA kit(Macherey-Nagel, Duren, Germany) and reverse-transcribed byMMLV reverse transcriptase (200 U) using random hexamers.Reverse transcribed products were amplified by RT-qPCR MasterMix (Life Technologies) and TaqMan assays (Applied Biosystems,Hammonton, NJ, USA) for each of the human genes tested. Actinwas used as a housekeeping gene. Relative gene expression wascalculated as 2-_Ct(_Ct $=\mathrm{Ct}$ of the target gene minus Ct of actin).

\section{Western blot analysis}

Confluent, serum-starved cells were treated with the appropri-ate conditions, quickly placed on ice, and washed with ice-coldphosphate-buffered saline. SDS-PAGE, transfer, and Western blot-ting were performed as described elsewhere [19].

\section{Measurement of Procollagen type 1 secretion}

Serum-deprived cells were treated with myostatin in the pres-ence or absence of the JNK inhibitor, SP600125 for $48 \mathrm{~h}$. At the endof the incubation, conditioned media were collected and stored at $-20 \circ \mathrm{C}$ until assayed. Type 1 procollagen was measured using aC-peptide enzyme immunoassay kit (Takara Bio Inc., Otsu, Shiga,Japan).

\section{RNA interference}

Transfection of primary HSC was performed by Amaxa nucleo-fection technology (Amaxa, Koln, Germany) as previously described[20], using $100 \mathrm{nM}$ small interfering RNA (siRNA) targeting JNK orTGF-B-B, or control non-targeting siRNA (all provided by Dharma-con Inc., Lafayette, CO). The efficiency of silencing was evaluatedby immunoblotting (JNK) or RT- PCR (TGF-B).

\section{In vivo studies}

C57Bl/6 mice, 8 weeks of age, were purchased from Charles RiverLaboratories (Calco, Italy). All animals received humane care andexperimental protocols were conducted according to Internationalguidelines (Guide for the Care and Use of Laboratory Animals, NIHpublication No. 86-23), after authorization by the local regulatoryauthorities. Two different models were employed.A first group of mice was administered a single intragastric dose $(1 \mathrm{ml} / \mathrm{kg})$ of CCl4diluted in mineral oil (1:5, v/v) and sacrificed after24, 48, or $72 \mathrm{~h}$. Control mice received an equal volume of mineraloil. In a second model, mice were fed either a high-fat diet deficientin methionine and 
choline (MCD), or a control diet supplementedwith methionine and choline (CD) for 10 weeks. Diets were fromLaboratori Dottori Piccioni (Milan, Italy). At the end of the experi-mental procedures, mice were euthanized by exsanguination under anesthesia, livers were rapidly dissected out, snap frozen in liquidnitrogen and stored at $-80{ }^{\circ} \mathrm{C}$ for RNA extraction. At least five micefor each experimental condition were analyzed.

\section{Immunohistochemistry}

The source of human liver tissue was previously reported [21].In addition, two animal models of chronic injury were analyzed.Mice were fed a MCD diet, as described above, or treated withchronic CCl4administration. This latter set of animals was admin-istered $0.5 \mathrm{ml} / \mathrm{kg}$ CCl4two times a week for six weeks, and thensacrificed as indicated above. Staining was performed essentiallyas described elsewhere [22]. Antigen retrieval was performed byheating in citrate buffer, $\mathrm{pH} 6.0$ at $98^{\circ} \mathrm{C}$ for $30 \mathrm{~min}$. Non-specificsignal was eliminated by peroxidase block for $10 \mathrm{~min}$ at room temperature. Primary antibody was incubated at room temperature(1 hour) at a 1:1000 dilution in a humidified chamber, followed byincubation with a Horseradish peroxidase (HRP)-conjugated secondary antibody for $20 \mathrm{~min}$ at room temperature. Antibody bindingwas revealed by 3,30diaminobenzidine and reaction was stoppedby immersion of tissue sections in distilled water once the browncolour appeared. Tissue sections were counterstained by hema-toxylin and mounted. All reagents for immunohistochemistry werefrom Dako.

\section{Measurement of myostatin levels}

Determination of the levels of myostatin in serum and in cytoso-lic fractions obtained from liver tissues was carried out in a mousemodel of acute liver damage induced by CCl4administration, asdescribed above. A mouse MSTN/GDF8/myostatin Elisa kit (LSBio,Seattle, WA, USA) was employed.

\section{Statistical analysis}

Data in bar graphs represent means \pm SD from at least threeindependent experiments. Luminograms are representative of atleast three experiments with similar results. Statistical analysis wasperformed using Student's t test. P values $<0.05$ were consideredsignificant). 


\section{Results}

We first analyzed the expression of ActR2B, which binds myo-statin, in experimental models of liver injury and fibrosis. A singleadministration of carbon tetrachloride in mice induces an acutedamage associated with activation of a transient repair process sim-ilar to the one activated during chronic liver injury [23]. At all timepoints tested after CCl4administration, gene expression of ActR2Bwas markedly and significantly increased compared to mice treatedwith vehicle (Fig. 1A). We next evaluated expression of ActR2B in amodel of fibrosis associated with steatohepatitis, after administra-tion of a diet deficient in methionine and choline for 10 weeks [24].This model causes pericentral fibrosis similar to the one observedin nonalcoholic steatohepatitis. Expression of ActR2B was dramat-ically increased in mice administered the fibrogenic diet comparedto those receiving the control diet, supplemented with methionineand choline (Fig. 1B).We also tested the expression of ActR2B at the tissue levelusing immunohistochemistry, in two mouse models of chronic liverinjury (Fig. 1C). In mice chronically intoxicated with CCl4, increasedexpression of ActR2B was evident in areas of inflammation andformation of the fibrotic septum. In mice fed a methionine andcholine-deficient diet for 10 weeks, a diffuse increase in Act2Rexpression was evident, also involving areas of pericentral fibrosis. To examine whether HSC, the major cellular players in the fibro-genic process, contribute to expression of ActR2B, we evaluatedgene expression of this receptor in different preparations of pri-mary human HSC and in LX-2, a human immortalized HSC line. HSCexpressed detectable transcripts for ActR2B (Fig. 1D), which, however, were not regulated by exposure to recombinant myostatinfor as long as $24 \mathrm{~h}$ (data not shown). To investigate the pattern ofActR2B expression in human liver tissue, samples from patientswith NASH-related fibrosis were stained with specific antibodies(Fig. 1E). Specific staining was diffusely present in hepatocytes andwithin the fibrotic septum. Staining of serial sections with anti_-smooth muscle actin antibodies, which detect activated HSC,demonstrated partial co-localization of the immunohistochemicalsignal, indicating that fibrogenic HSC contribute to ActR2B expression in the fibrotic liver (Fig. 1E). Collectively, these data indicatethat the receptor for myostatin is upregulated in conditions associ-ated with fibrogenic repair of liver tissue, and that HSC contributeto expression of ActR2B.

We then explored whether myostatin levels are modulated inconditions of experimental liver injury. In mice with acute liverinjury caused by CCl4administration (Fig. 2A), serum levels ofmyostatin were significantly increased at early time points aftertoxin administration. In contrast, no significant differences wereobserved when myostatin levels were assayed in liver tissue lysates(Fig. 
2B).Having shown that HSC express ActR2B, we next investigatedwhether myostatin modifies the biology of these cells after bindingto its cognate receptor. Proliferation and migration of HSC are piv-otal actions which contribute to their pro-fibrogenic phenotype,although cytokines may differentially regulate these processes.Exposure of LX-2 to myostatin resulted in a significant reduction incell proliferation, as established measuring the cellular metabolicactivity (Fig. 3A). In contrast, PDGF-BB, used as a positive control,significantly increased proliferation. Migration of HSC is critical todetermine accumulation of fibrogenic cells in discrete areas of thehepatic acinus, resulting in deposition of scar tissue in differentregions, according to the etiology of chronic liver disease. Exposureto increasing concentrations of myostatin resulted in a signifi-cant increase in cell migration, which was similar, at the $50 \mathrm{ng} /$ mlconcentration, to the one achieved in response to PDGF-BB, themost potent motogenic stimulus for this cell type (Fig. 3B-C). Ofnote, comparable results were observed in LX-2, an immortalizedhuman HSC line, and in primary HSC, albeit minor differences inthe response to myostatin were observed.

Increased expression of factors implicated in matrix turnover isanother characteristic of activated HSC, and is modulated by dif-ferent soluble factors. We first tested whether myostatin has theability to regulate the expression of type 1 procollagen, a fibrillarcomponent of extracellular matrix abundant in the fibrotic liver.Exposure to myostatin resulted in a significant increase in procollagen expression (Fig. 4A). Of note, myostatin was also able toinduce a significant increase in the secretion of procollagen 1 inthe culture supernatant (Fig. 6). The expression of TGF-B1, one ofthe most potent fibrogenic cytokine, was also significantly upreg-ulated when HSC were exposed to myostatin (Fig. 4A). Finally,myostatin upregulated TIMP-1 gene expression, indicating thatreduced matrix turnover could contribute to the fibrogenic effectsof this factor (Fig. 4C). Taken together, these data indicate a directprofibrogenic role of myostatin, via induction of factors implicatedin matrix turnover.ActR2B belongs to the TGF-B receptors superfamily, and theeffects of myostatin are similar to those exerted by TGF-B onHSC. Moreover, myostatin increases expression of TGF-B1 (Fig. 4B).To establish whether myostatin acts inducing an upregulation ofTGF-B secretion by HSC, we silenced TGF-B-1 with siRNA and incu-bated the cells in the presence or absence of myostatin (Table 1).The effects of myostatin on both migration and proliferation ofHSC were maintained after TGF-B-1 knockdown, indicating thatincreased expression of TGF-B1 is not necessary for the motogenicand anti-proliferative actions of myostatin.Modification of the biologic properties of HSC is dependent onspecific changes in different intracellular signaling pathways [25].We tested whether myostatin modifies the activation of kinasesFig. 3. Myostatin induces growth-inhibition and promotes migration in HSC. (A)Serum-deprived LX-2 were left untreated (white bars), exposed to different con-centrations of myostatin (50 ng/ml, grey bars, $100 \mathrm{ng} / \mathrm{ml}$, 
black bars) or $10 \mathrm{ng} / \mathrm{mlPDGF-BB}$ (crossed-hatched bars, positive control) for 24, 48, and $72 \mathrm{~h}$. Cell prolif-eration was determined by MTT assay. Results are expressed as optical densityvalues. Data are mean $\pm \mathrm{SD}$ of three independent experiments. ${ }^{*} \mathrm{P}<0.05$ vs Cnt. (B-C)Migration of LX-2 (B) or primary HSC (C) in response to indicated concentration ofmyostatin was evaluated using Boyden chambers. Data are the mean $\pm \mathrm{SD}$ of fourexperiments. ${ }^{*} \mathrm{P}<0.05$ vs Cnt.implicated in the regulation of the fibrogenic phenotype of HSC.Exposure to myostatin resulted in a rapid and significant increasein the activation of JNK (Fig. 5A). In contrast, activation of ERK1/2,another member of the mitogen-activated protein kinase family,and of Akt (Fig. 5B), was only modestly upregulated by myostatin.We next analyzed the possible effects of myostatin on the acti-vation of Smad3, an intracellular protein critically implicated inthe regulation of extracellular matrix turnover. Phosphorylation ofSmad3 on activation-specific residues was dramatically increasedin cells incubated with myostatin (Fig. 5C). These results providea link between myostatin and activation of intracellular pathwayslinked to expression of collagen and other matrix components.Activation of JNK represents a pathway associated with a profi-brogenic phenotype of HSC [26]. Thus, we focused on the role of thiskinase in the processes triggered by myostatin in HSC. In the presence of SP600125, a specific inhibitor of JNK activation, the abilityof myostatin to induce migration of HSC was markedly and sig-nificantly blunted (Fig. 6A-B). Noteworthy, comparable data wereobtained in the LX-2 cell line and in primary human HSC.

Moreover,SP600125 reduced secretion of procollagen type 1 in the culturemedium of myostatinstimulated HSC (Fig. 6C-D). To further sup-port these findings, we performed genetic silencing of JNK usingspecific siRNAs. This strategy determined a 50\% decrease in JNKabundance (Fig. 7A). In these conditions, exposure to myostatinwas significantly less effective in causing migration of HSC (Fig. 7B).Taken together, these data provide evidence that JNK activationis necessary to mediate the effects of myostatin on the fibrogenicphenotype of HSC.

\section{Discussion}

This study provides the first demonstration of a direct linkbetween myostatin, a myokine, and the process of hepatic fibrogen-esis. We found that myostatin modulates several biologic actions of HSC relevant for the fibrogenic process, and specifically cell migra-tion and expression of molecules implicated in matrix turnover, atthe gene expression and protein levels. Of note, the effects of myo-statin resembled those of TGF-B- _, a protein of the same superfamily.Similar to TGF-B- _, myostatin caused growth arrest of HSC, while itup-regulated several factors implicated in fibrogenesis [27]. Finally,increased procollagen secretion was detected in cells exposed 
tomyostatin. While these actions resemble those elicited by TGF-B- _, myostatin appears to act in an independent fashion, as geneticknockdown of TGF-B-_1 in HSC did not result in any changes in theeffects of myostatin on cell migration or proliferation.Of note, dataobtained in LX-2, an immortalized HSC line, were replicated in pri-mary HSC, albeit with minor quantitative differences, providingadditional evidence to the present results.Data obtained in the past decade has highlighted the importantconcept that the fibrogenic process may be modulated by stimuligenerated outside the liver [28]. Adipokines, i.e. cytokines mainlyexpressed in the adipose tissue, include leptin and adiponectin, which regulate fibrogenesis and HSC biology in opposite fashions[29]. More recently, the possibility that alterations in the microbiotaresult in modulation of fibrosis has been experimentally proven[30]. Data provided herein provide the first, proof-of-concept evi-dence that myokines represent an additional family of factorspotentially modulating fibrogenesis from outside the liver.

Several recent studies have highlighted the possibility that themuscle-liver axis is very likely to play a relevant role in the patho-genesis of the metabolic syndrome. Sarcopenia in patients withNAFLD correlates with the degree of liver damage, and specificallywith fibrosis [31]. In addition, reduced muscle mass is a hallmarkof patients with alcoholic liver disease, and is common in cirrhosis[32]. In these conditions, where myostatin has been shown to beelevated in the systemic circulation, this factor could be a relevantmediator of accelerated fibrogenesis. Circulating myostatin levelsin healthy subjects are around $40 \mathrm{ng} / \mathrm{ml}$ [33], and therefore the con-centrations used in our in vitro experiments (50-100 ng/ml) are ina similar range. Remarkably, very similar levels were found in theserum of control mice, whereas myostatin concentrations almostdoubled in conditions of acute liver injury.Data obtained in this study also provide insight on the intra-cellular signaling pathways implicated in the transmission of thefibrogenic signal by myostatin in HSC. Primary HSC and LX-2 werefound to express ActR2B, the specific receptor for myostatin, iden-tifying HSC as a target of myostatin's action. HSC appeared tocontribute to ActR2B expression also in human liver tissue frompatients with NASH and fibrosis, although other cells were alsopositively stained for this receptor.We next focused on proteins of the MAPK family and on Akt,which have been shown to play relevant roles in mediating theeffects of different fibrogenic factors [25]. Myostatin only modestly activated Akt, or members of the MAPK family such as ERK1/2and p38MAPK. In contrast, a marked and consistent activation ofJNK was observed. JNK, and particularly JNK-1, has been shownto be implicated in the fibrogenic process, both in vitro and inanimal models [26]. In particular, several studies have indicatedthe ability of JNK activation in HSC to activate downstream path-ways, regulating multiple actions relevant for fibrogenesis, suchas cell proliferation, oxidative stress, and expression of profibro-genic factors [34,35]. We used both a 
pharmacologic approach withthe specific inhibitor SP600125 and a genetic approach with JNK-1 knockdown by siRNA. In both cases, the ability of myostatin toinduce cell migration and to upregulate collagen secretion wassignificantly reduced, both in LX-2 and in primary HSC. Remarkably, only limited evidence had previously linked myostatin withactivation of JNK. In C2C12 murine myoblasts, exposure to myostatin activates JNK, which mediated the growth inhibitory signalinduced by this cytokine [36]. As myostatin has been linked to fibro-sis in other tissues, but not in the liver, data reported herein arethe first example of a myostatin-JNK-myofibroblast axis regulatingfibrogenesis.In other systems, myostatin has been linked to the biology offibrogenic cells. Overexpression of myostatin in cardiomyocytesresulted in altered cardiac function in older mice and in inter-stitial fibrosis, through activation of the p38MAPKpathway [37].Moreover, myostatin has been implicated in the pathogenesis offibrosis in skeletal muscle, where it induces fibroblast proliferationand secretion of extracellular matrix [38] and increases fibroblastresistance to apoptosis [39], via activation of Smad and p38MAPKsignaling. Myostatin also promoted the differentiation of musclefibroblasts into myofibroblasts, and induced expression of TGF-B- _ inmyofibers [40]. In vivo, induction of muscular damage in myostatin-deficient mice was associated with increased regeneration andreduced fibrosis. Nonetheless, the fibrogenic action of myostatindoes not appear to be limited to muscle tissue, as myostatin hasbeen involved in the pathogenesis of experimental Peyronie's dis-ease in the rat [41]. Myostatin was also found to be expressed inthe skin, and myostatin-deficient mice showed reduced healing ofcutaneous wounds due to impaired myofibroblast differentiation,resulting in delayed contraction of the wound [42]. The identifica-tion of myostatin as a mediator of fibrosis in other tissues supportsour finding of its profibrogenic activity in hepatic myofibroblasts.A few limitations of this study must be acknowledged. In particular, the relevance of the myostatin system in vivo was onlyexplored analyzing the expression of ActR2B in models of liverrepair and fibrogenesis. While the marked upregulation of the myo-statin receptor in conditions of fibrogenic liver injury argues infavor of a pathogenic role of this factor, it does not provide in vivomechanistic evidence. On the other hand, this is not easy to obtaindue to the limited availability of pharmacologic blockers of myo-statin's action and to the fact that myostatindeficient mice havea complex phenotype that makes it difficult to single out a directprofibrogenic effect. Nonetheless, extension of these studies withexperiments modulating the actions of myostatin in vivo is war-ranted in the near future.In conclusion, we have shown that myostatin, a protein whichinhibits growth of skeletal muscle, modulates the biologic proper-ties of human HSC in a profibrogenic fashion, via activation of JNK.These data identify a novel muscle-to-liver pathway potentiallyimplicated in the pathogenesis of hepatic fibrosis in conditions suchas NAFLD and alcoholic liver disease. 


\section{References}

[1] Sharma M, McFarlane C, Kambadur R, Kukreti H, Bonala S, Srinivasan S. Myo-statin: expanding horizons. IUBMB Life 2015;67:589-600.

[2] McPherron AC, Lawler AM, Lee SJ. Regulation of skeletal muscle mass in miceby a new TGFB-beta superfamily member. Nature 1997;387:83-90.

[3] Fearon KC, Glass DJ, Guttridge DC. Cancer cachexia: mediators, signaling, andmetabolic pathways. Cell Metab 2012;16:153-66.

[4] Huang Z, Chen X, Chen D. Myostatin: a novel insight into its role in metabolism,signal pathways, and expression regulation. Cell Signal 2011;23:1441-6.

[5] Wilkes JJ, Lloyd DJ, Gekakis N. Loss-of-function mutation in myostatin reducestumor necrosis factor alpha production and protects liver against obesity-induced insulin resistance. Diabetes 2009;58:1133-43.

[6] McPherron AC, Lee SJ. Suppression of body fat accumulation in myostatin-deficient mice. J Clin Invest 2002;109:595-601.

[7] Milan G, Dalla Nora E, Pilon C, Pagano C, Granzotto M, Manco M, et al. Changesin muscle myostatin expression in obese subjects after weight loss. J ClinEndocrinol Metab 2004;89:2724-7. [8] Palsgaard J, Brons C, Friedrichsen M, Dominguez H, Jensen M, Storgaard H, et al.Gene expression in skeletal muscle biopsies from people with type 2 diabetesand relatives: differential regulation of insulin signaling pathways. PLoS One2009;4:e6575.

[9] Jornayvaz FR, Samuel VT, Shulman GI. The role of muscle insulin resistance inthe pathogenesis of atherogenic dyslipidemia and nonalcoholic fatty liver dis-ease associated with the metabolic syndrome. Annu Rev Nutr 2010;30:273-90.

[10] Rosselli M, Lotersztajn S, Vizzutti F, Arena U, Pinzani M, Marra F. The metabolicsyndrome and chronic liver disease. Curr Pharm Des 2014;20:5010-24.

[11] Ahmed A, Wong RJ, Harrison SA. Nonalcoholic fatty liver disease review: diag-nosis, treatment, and outcomes. Clin Gastroenterol Hepatol 2015;13:2062-70.

[12] Ekstedt M, Hagstrom H, Nasr P, Fredrikson M, Stal P, Kechagias S, et al. Fibrosisstage is the strongest predictor for disease-specific mortality in NAFLD after upto 33 years of follow-up. Hepatology 2015;61:1547-54.

[13] Angulo P, Kleiner DE, Dam-Larsen S, Adams LA, Bjornsson ES, Charatcharoen-witthaya P, et al. Liver fibrosis, but no other histologic features, is associatedwith long-term outcomes of patients with nonalcoholic fatty liver disease.Gastroenterology 2015;149, 389-397 e10. 
[14] Trautwein C, Friedman SL, Schuppan D, Pinzani M. Hepatic fibrosis: concept totreatment. J Hepatol 2015;62:S15-24.

[15] Mederacke I, Hsu CC, Troeger JS, Huebener P, Mu X, Dapito DH, et al. Fatetracing reveals hepatic stellate cells as dominant contributors to liver fibrosisindependent of its aetiology. Nat Commun 2013;4:2823.

[16] Wallace MC, Friedman SL, Mann DA. Emerging and disease-specific mecha-nisms of hepatic stellate cell activation. Semin Liver Dis 2015;35:107-18.

[17] Petta S, Valenti L, Marra F, Grimaudo S, Tripodo C, Bugianesi E, et al. MERTKrs4374383 polymorphism affects the severity of fibrosis in non-alcoholic fattyliver disease. J Hepatol 2016;64:682-90.

[18] Di Maira G, Brustolon F, Tosoni K, Belli S, Kramer SD, Pinna LA, et al. Compar-ative analysis of CK2 expression and function in tumor cell lines displayingsensitivity vs: resistance to chemical induced apoptosis. Mol Cell Biochem2008;316:155-61.

[19] Rovida E, Di Maira G, Tusa I, Cannito S, Paternostro C, Navari N, et al. Themitogen-activated protein kinase ERK5 regulates the development and growthof hepatocellular carcinoma. Gut 2015;64:1454-65.

[20] Caligiuri A, Bertolani C, Guerra CT, Aleffi S, Galastri S, Trappoliere M, et al.Adenosine monophosphate-activated protein kinase modulates the activatedphenotype of hepatic stellate cells. Hepatology 2008;47:668-76.

[21] Locatelli I, Sutti S, Jindal A, Vacchiano M, Bozzola C, Reutelingsperger C, et al.Endogenous annexin A1 is a novel protective determinant in nonalcoholicsteatohepatitis in mice. Hepatology 2014;60:531-44.

[22] Carloni V, Lulli M, Madiai S, Mello T, Hall A, Luong TV, et al. CHK2 overex-pression and mislocalisation within mitotic structures enhances chromosomalinstability and hepatocellular carcinoma progression. Gut 2018;67:348-61.

[23] Marra F, Gentilini A, Pinzani M, Choudhury GG, Parola M, Herbst H, et al.Phosphatidylinositol 3-kinase is required for platelet-derived growth factor'sactions on hepatic stellate cells. Gastroenterology 1997;112:1297-306.

[24] Vizzutti F, Provenzano A, Galastri S, Milani S, Delogu W, Novo E, et al. Cur-cumin limits the fibrogenic evolution of experimental steatohepatitis. LabInvest 2010;90:104-15.

[25] Caligiuri A, Marra F. Stellate cells. In: Dufour JF, Clavien PA, editors. Signalingpathways in liver diseases. Chichester: John Wiley \& Sons; 2015. p. 34-60.

[26] Seki E, Brenner DA, Karin M. A liver full of JNK: signaling in regulation of cellfunction and disease pathogenesis, and clinical approaches. Gastroenterology2012;143:307-20. 
[27] Friedman SL. Hepatic stellate cells: protean, multifunctional, and enigmaticcells of the liver. Physiol Rev 2008;88:125-72.

[28] Caligiuri A, Gentilini A, Marra F. Molecular pathogenesis of NASH. Int J Mol

Sci2016:17.[29] Marra F, Bertolani C. Adipokines in liver diseases. Hepatology 2009;50:957-69.

[30] De Minicis S, Rychlicki C, Agostinelli L, Saccomanno S, Candelaresi C, Trozzi L,et al.

Dysbiosis contributes to fibrogenesis in the course of chronic liver injuryin mice. Hepatology 2014;59:1738-49.

[31] Petta S, Ciminnisi S, Di Marco V, Cabibi D, Camma C, Licata A, et al. Sarcopeniais associated with severe liver fibrosis in patients with non-alcoholic fatty liverdisease. Aliment Pharmacol Ther 2017;45:510-8.

[32] Dasarathy S, Merli M. Sarcopenia from mechanism to diagnosis and treatmentin liver disease. J Hepatol 2016;65:1232-44.

[33] Gruson D, Ahn SA, Ketelslegers JM, Rousseau MF. Increased plasma myostatinin heart failure. Eur J Heart Fail 2011;13:734-6.[34] Novo E, Povero D, Busletta C, Paternostro C, di Bonzo LV, Cannito S, et al. Thebiphasic nature of hypoxia-induced directional migration of activated humanhepatic stellate cells. J Pathol 2012;226:588-97.

[35] Fabre T, Kared H, Friedman SL, Shoukry NH. IL-17A enhances the expressionof profibrotic genes through upregulation of the TGF-B-beta receptor on hepaticstellate cells in a JNK-dependent manner. J Immunol 2014;193:3925-33.

[36] Huang Z, Chen D, Zhang K, Yu B, Chen X, Meng J. Regulation of myostatin sig-naling by cJun N-terminal kinase in C2C12 cells. Cell Signal 2007;19:2286-95.

[37] Biesemann N, Mendler L, Kostin S, Wietelmann A, Borchardt T, Braun T. Myo-statin induces interstitial fibrosis in the heart via TAK1 and p38. Cell Tissue Res2015;361:779-87.

[38] Li ZB, Kollias HD, Wagner KR. Myostatin directly regulates skeletal musclefibrosis. J Biol Chem 2008;283:19371-8.[39] Bo Li Z, Zhang J, Wagner KR. Inhibition of myostatin reverses muscle fibrosisthrough apoptosis. J Cell Sci 2012;125:3957-65.

[40] Zhu J, Li Y, Shen W, Qiao C, Ambrosio F, Lavasani M, et al. Relationships betweentransforming growth factor-beta1, myostatin, and decorin: implications forskeletal muscle fibrosis. J Biol Chem 2007;282:25852-63.

[41] Cantini LP, Ferrini MG, Vernet D, Magee TR, Qian A, Gelfand RA, et al. Profibroticrole of myostatin in Peyronie’s disease. J Sex Med 2008;5:1607-22.[42] Zhang C, Tan CK, McFarlane C, Sharma M, Tan NS, Kambadur R. Myostatin-nullmice exhibit delayed skin wound healing through the blockade of trans-forming growth factor-beta signaling by decorin. Am J Physiol Cell Physiol2012;302:C1213-25. 


\section{Tables}

Table 1. Effects of TGF-B- B1 silencing on myostatin-induced proliferation and migration of HSC.

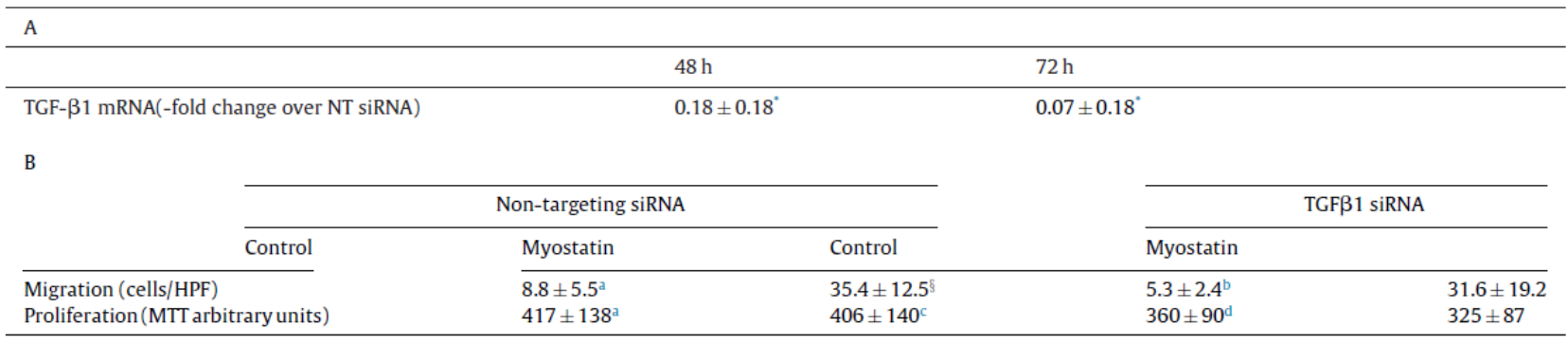

(A): LX-2 cells were transfected with siRNA for the indicated time points, and gene expression of cells transfected with siRNA directed against TGF-B1 was compared to the one of cells transfected with nontargeting siRNA. (B) LX-2 cells were transfected with siRNA as indicated, and incubated in the presence or absence of $50 \mathrm{ng} / \mathrm{ml}$ myostatin. Analysis of cell migration and proliferation were performed as described in Materials and Methods. aP $<0.05$ vs. myostatin and non-targeting siRNA.bP $=0.07$ vs. myostatin and TGFB1 siRNA.cP = NS vs. myostatin and TGF-B1 siRNA.dP $<0.05$ vs. myostatin and TGF- B1 siRNA. HPF, high-power field. $* \mathrm{P}<0.01$. 


\section{Figures}

Fig. 1. Hepatic expression of the myostatin receptor ActR2B in experimental liver injury, in human HSC, and in human liver tissue.
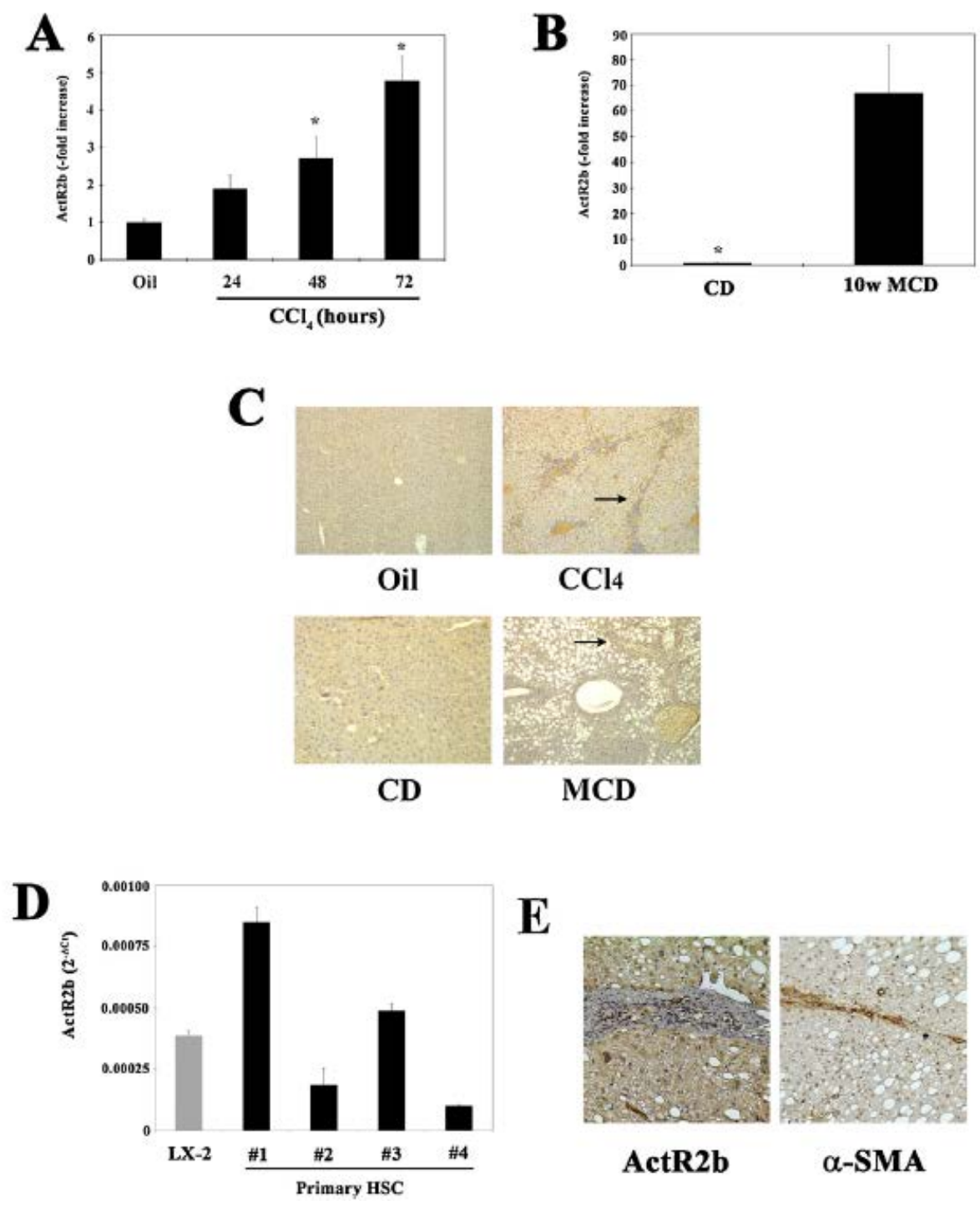

(A) C57Bl/6 mice ( $\mathrm{n} \geq 3$ ) were orallyadministered CCl4 $(1 \mathrm{ml} / \mathrm{kg}$ ) or vehicle (olive oil) for the indicated time periods. (B) C57Bl/6 mice ( $\mathrm{n} \geq 3$ ) were fed a methionine and choline deficient diet (MCD) or a controldiet (CD) for 10 weeks. Total RNA was isolated from liver tissue and the expression of ActR2B was determined by qRT-PCR. Target gene expression was normalized to GAPDH.Data are expressed as -fold increase over control. *P $<0.05$ vs. control. (C) Top panels: mice were treated with mineral oil or with CCl4for 6 weeks, as described in Materialsand Methods. Bottom panels: mice were fed with a control diet (CD) or a diet deficient in methionine and choline (MCD) for 10 weeks. Slides were stained with antibodiesagainst ActR2B. Arrows indicate areas of fibrogenesis. (D) Total RNA was isolated from the human HSC line, LX2, and from different preparations of primary HSC. mRNAexpression of Act2Rb was evaluated by qRTPCR. Relative gene expression was calculated as 2-_Ct(_Ct=Ctof the target $-\mathrm{Ctof}$ _actin). (E) Serial 
sections of liver tissuefrom a patient with NASH and fibrosis were stained with antibodies against ActR2b (left) or _-smooth muscle actin (right), a marker of activated HSC. Brown color showspartial co-localization between the two stainings in the fibrotic septum. 
Fig. 2. Serum and hepatic levels of myostatin in conditions of liver injury. Mice were treated with mineral oil (control) or with a single intragastric administrationof $1.0 \mathrm{ml} / \mathrm{kg}$ CCl4and sacrificed after the indicated periods of time. Myostatin levelswere analyzed in serum (A) and in tissue lysates (B) as indicated in Materials andMethods. Data are mean \pm SD of at least three mice per group. ${ }^{*} \mathrm{P}$ $<0.05$ vs. control(Oil).
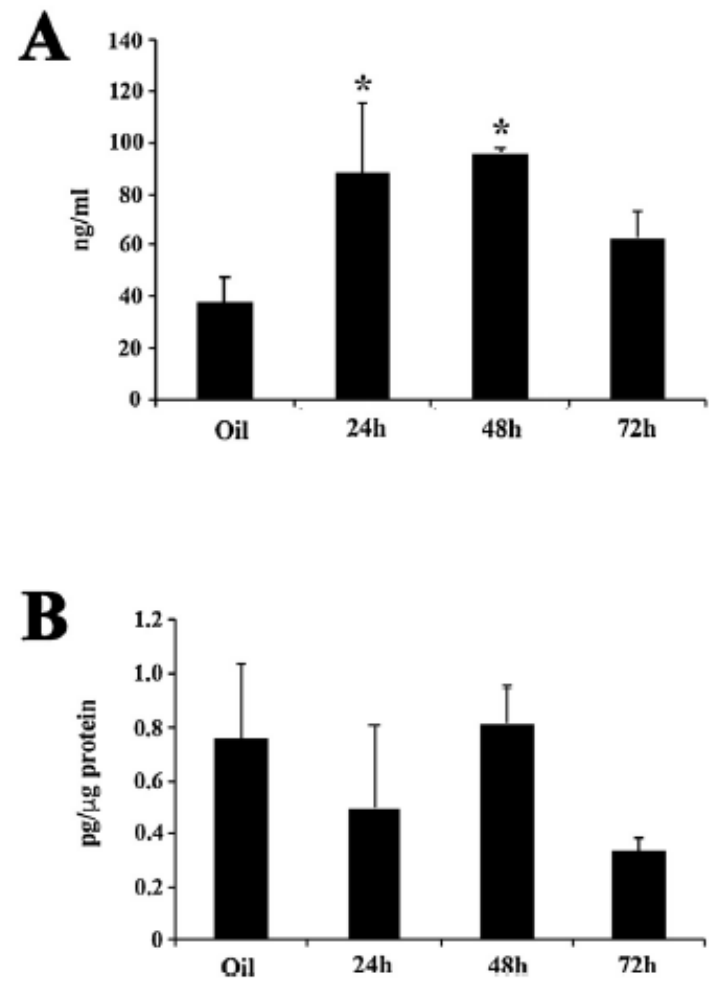
Fig. 3. Myostatin induces growth-inhibition and promotes migration in HSC.
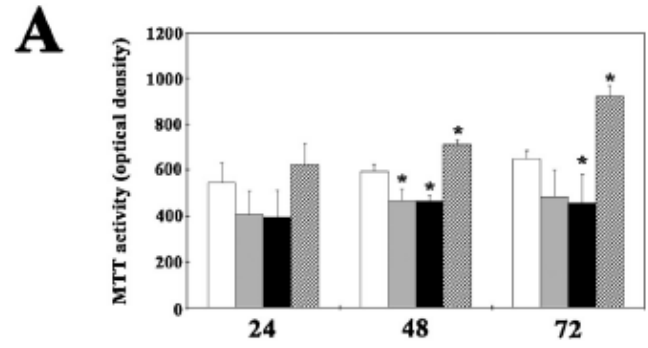

B
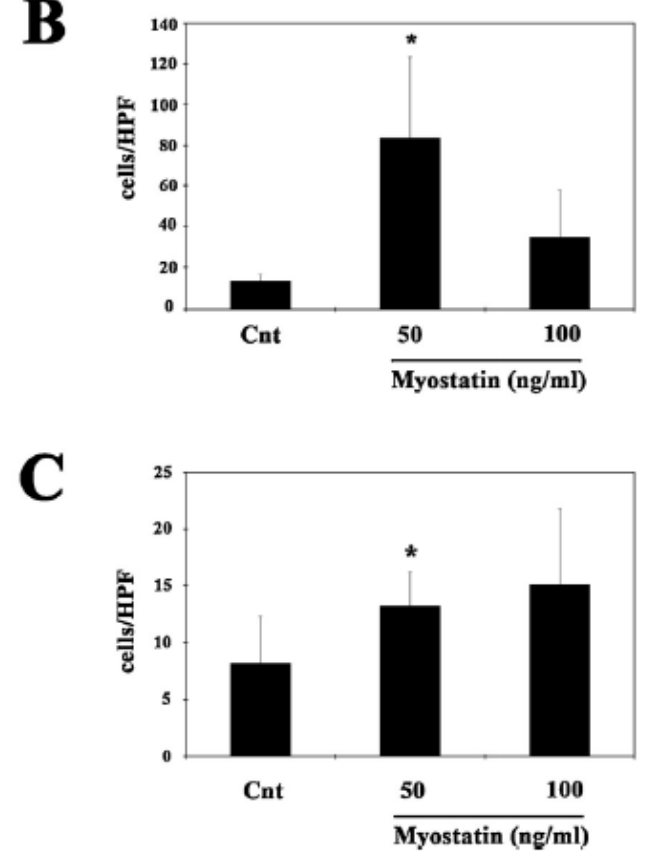

(A)Serum-deprived LX-2 were left untreated (white bars), exposed to different con-centrations of myostatin ( $50 \mathrm{ng} / \mathrm{ml}$, grey bars, $100 \mathrm{ng} / \mathrm{ml}$, black bars) or $10 \mathrm{ng} / \mathrm{mlPDGF}-\mathrm{BB}$ (crossed-hatched bars, positive control) for 24, 48, and $72 \mathrm{~h}$. Cell prolif-eration was determined by MTT assay. Results are expressed as optical densityvalues. Data are mean \pm SD of three independent experiments. $* \mathrm{P}<0.05$ vs Cnt. (B-C)Migration of LX-2 (B) or primary HSC (C) in response to indicated concentration ofmyostatin was evaluated using Boyden chambers. Data are the mean \pm SD of fourexperiments. $* \mathrm{P}<0.05$ vs Cnt. 
Fig. 4. Myostatin positively modulates the expression of profibrogenic genes.
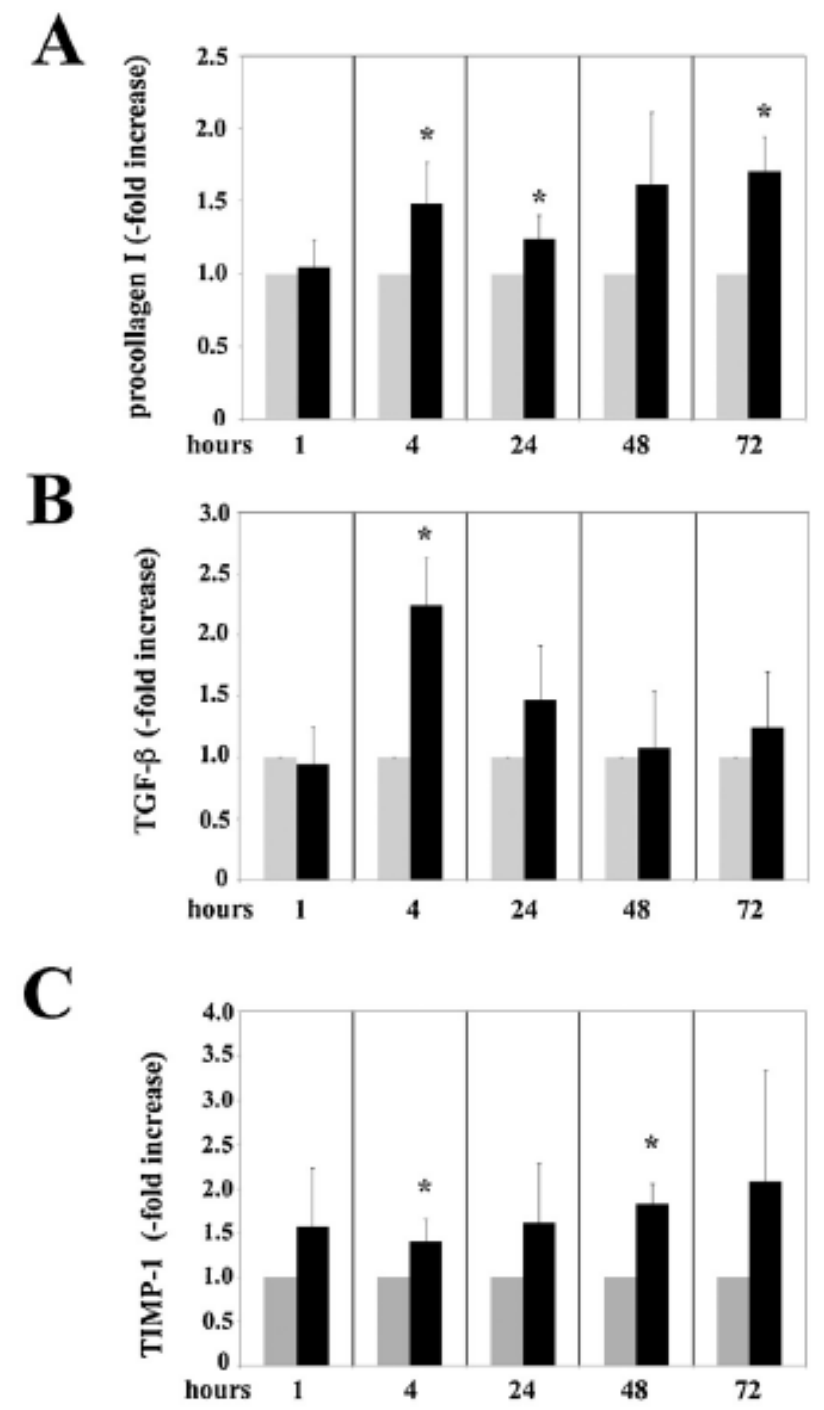

Serum-deprived LX-2 were incubated in the presence (black columns) or in theabsence (gray columns) of 50 $\mathrm{ng} / \mathrm{ml}$ myostatin for the indicated time points. TotalRNA was extracted and the expression of procollagen 1 (A), TGF-_1 (B) and TIMP-1(C) was determined by qRT-PCR. Target gene expression was normalized to actin.Results, expressed as fold increase over control, represent the mean value \pm SD ofthree independent experiments. ${ }^{*} \mathrm{P}<0.05$ vs the same time point in the absence ofmyostatin. 
Fig. 5. Signaling pathways activated by myostatin.

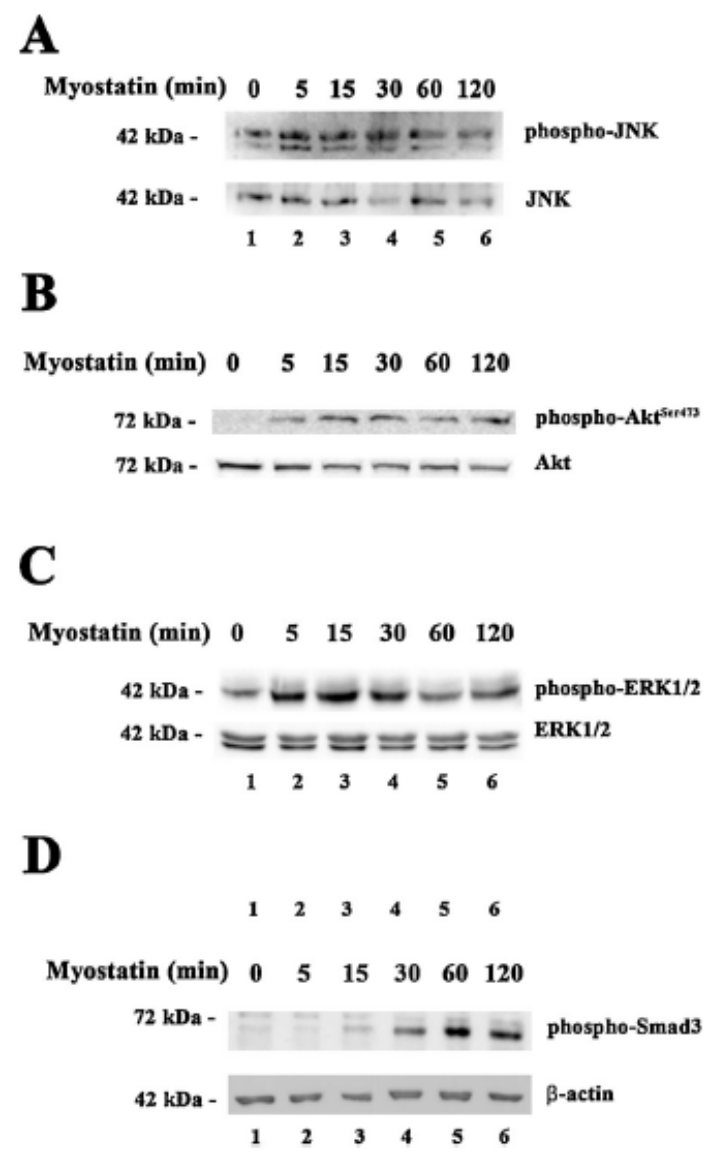

Serum-starved LX-2 cells wereexposed to $50 \mathrm{ng} / \mathrm{ml}$ myostatin for the indicated time points. Total cell lysates wereanalyzed by immunoblotting using antibodies directed against the phosphorylatedforms of JNK (A), Akt (B) ERK1/2 (C) or Smad-3 (D). Data from a single experimentrepresentative of at least three with similar results. 
Fig. 6. Biologic effects of myostatin in HSC are blocked by a JNK inhibitor.
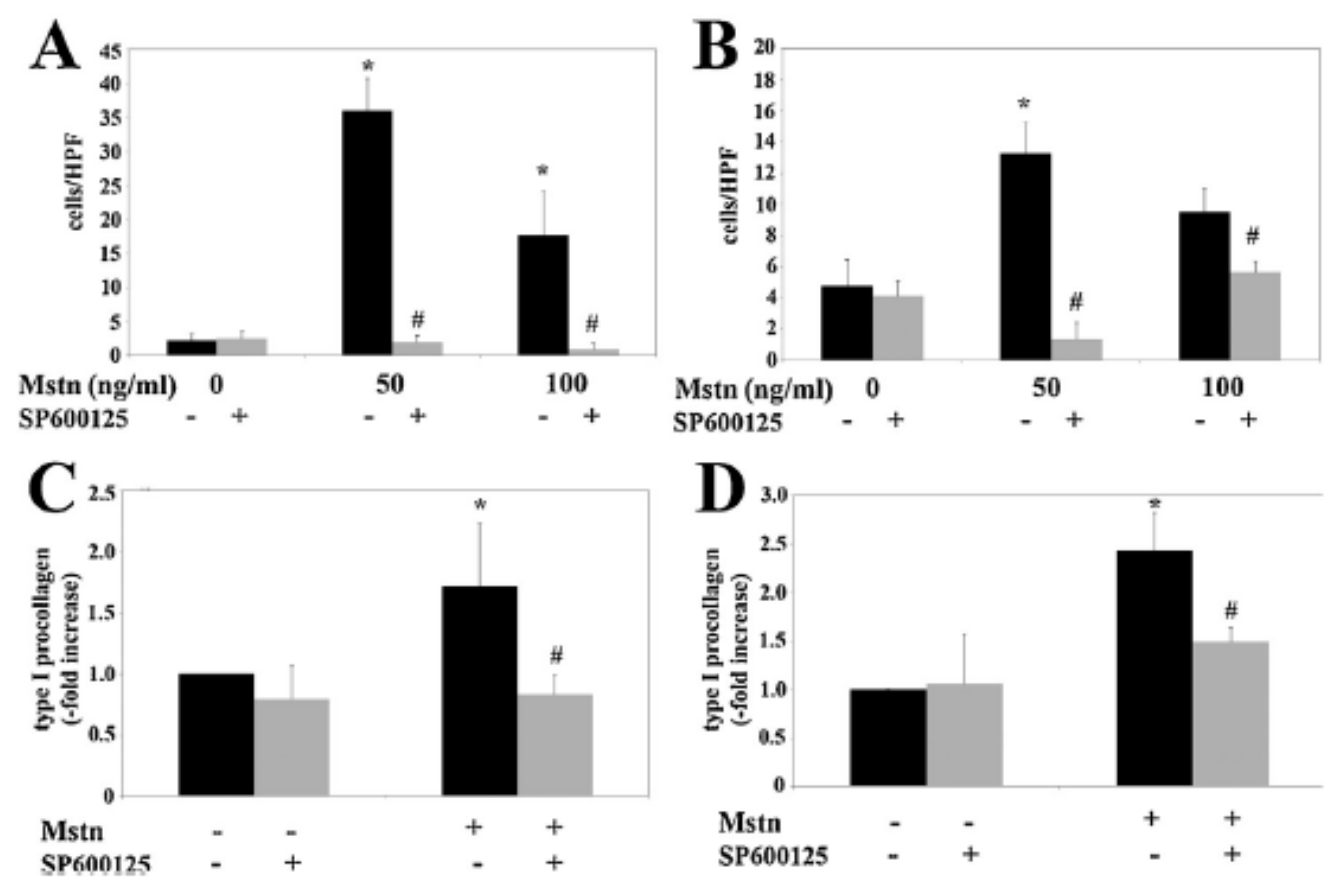

(A-B) Migration of LX-2 cells (A) or primary HSC (B) in response to myostatin (50-100 ng/ml)was evaluated in the presence or absence of the JNK inhibitor SP600125 (20_M), using Boyden chambers. Data are the mean \pm SD of three independent experiments. (C-D)Serum-starved LX-2 cells (C) or primary HSC (D) were treated with myostatin (50 ng/ml) in the presence or absence of 20 _M SP600125 for $48 \mathrm{~h}$. Procollagen type I secretionwas determined in cell supernatants by EIA. Results were normalized for total protein content in cell lysates. Data are expressed as fold change over control and indicate themean \pm SD of three independent experiments. $* \mathrm{P}<0.05 \mathrm{vs}$ Cnt; $\# \mathrm{P}<0.05$ vs myostatin (Mstn). 
Fig. 7. JNK is required for myostatin-induced biological actions in HSC.
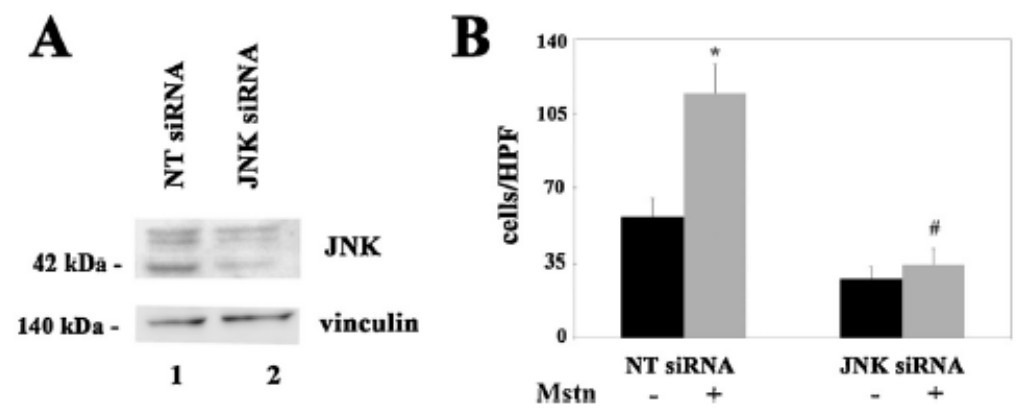

Knockdown of JNK in primary HSC was achieved by transfection of specific siRNA (JNK siRNA).Nontargeting siRNA (NT siRNA) were employed as control. (A) Transfection efficiency was evaluated by Western blotting using antibodies against JNK or vinculin, as controlfor equal loading. Data from a single experiment representative of three. (B) Cell migration in response to $50 \mathrm{ng} / \mathrm{ml}$ myostatin was tested in serum-starved HSC, $48 \mathrm{~h}$ followingtransfection. Data are the mean \pm SD of three independent experiments. $* \mathrm{P}<0.05$ vs Cnt; \#P $<0.05$ vs NT siRNA + myostatin (Mstn). 